Janapriya Journal of Interdisciplinary Studies, Vol. 6 (December 2017)

\title{
Research Article \\ Customers Satisfaction towards Life Insurance Claim Settlement in Nepal
}

\author{
Damodar Basaula \\ Janapriya Multiple Campus ,Pokhara \\ Email: basaula_42db@hotmail.com
}

\begin{abstract}
Claim settlement has been like a mirror to each life insurance companies which public see the real face of their business. A company which fails to settle the claim, the satisfaction of customers would definitely distracts the business and discourage to continue or the repurchase of policy. The main purpose of the research paper is to examine the awareness and satisfaction of customers towards life insurance claim settlement in Nepal. Descriptive research designed has been employed in the study. Sample comprises 391 respondent agents for which stratified sampling were used. Primary data were obtained through questionnaire method specifically the five point likert scale. The data collected for the study were analyzed thought SPSS software and MS Excel too. The study revealed that majority of the respondents has neutral response on the satisfaction towards claim settlement. However they think that the claim settlement process speed would definitely help to increase life insurance business. The study revealed that government should focus on awareness of life insurance and make it mandatory for every citizen
\end{abstract}

Keywords: Claim, life insurance, risk, satisfaction

\section{Introduction}

Human beings are exposed of various kinds of risk of uncertain, unexpected and unforeseen events such as untimely death, loss of properties by fire, theft and accident etc. which cause the financial losses. 
Application of Cost Reduction ...

Risks and events are uncertain. They cannot be eliminated but can be divided, managed and reduced significantly with the help of insurance. Insurance is the way of transferring a loss from one person to another person or institution in exchange of payment. Insurance company who sells insurance policy is insurer and policy holder is the insured who purchase insurance policy and shift the risk to the insurer (Singh, 2010).

Insurance is a means to minimize future uncertainty and financial losses. Acting as a risk transfer mechanism is the primary function of insurance (Holyoak\&Weipers, 2002). Rejda (2008) stated that sharing or pooling of losses is the heart of insurance, pooling is the spreading a losses incurred by the few over the entire group so that average loss is substituted for actual loss. Therefore, insurance is a co operative device to spread the loss caused by particular risk over a number of persons who are exposed to it and who agree to insure themselves against the risk.

The lack of awareness and having low income generation of people in Nepal, have hindered the saving intention in the life insurance though some people have saved in the form of cooperatives. Before the institutionalization of the insurance activities in Nepal, some foreign companies were involved in insurance business. Nepalese practice of insurance began when RatriyaBeema Sansthan (RBS) was established in 1968 in the form of government owned public insurance company.History of life insurance companies in Nepal was 46 years and till the date, total nine life insurance companies are operating life insurance business in Nepal and only around $9 \%$ people out of total population are insured till the date (Insurance Board, 2014). It is very sluggish growth of life insurance in Nepal as the life insurance has become one of the most important needs of every human being in the world.

Existing claim settlement practice done by the insurance companies also may be the cause of slow growth of life insurance in Nepal. Whether the life insurance companies are settling the claim fairly and timely, whether the people are satisfied or suffered from problem during the time of claim settlement may be the question to be solved. Claim settlement has been like 
Janapriya Journal of Interdisciplinary Studies, Vol. 6 (December 2017)

a mirror to each life insurance companies which public see the real face of their business. A company which fails to settle the claim, the satisfaction of customers would definitely distracts the business and discourage to continue or the repurchase of policy. Such dis satisfied client might even advice to their friends, relatives and other general public not to patronize such companies rather than appreciation of buying insurance policy.

The consequent problems may lead the life insurance company less selling of insurance policy and downward trend of reducing volume, low premium income collection, low capital formation and minimal contribution of life insurance companies to the gross domestic product of the country. Prudent claim administration strategy may promote customer loyalty as it helps to develop the perception of belongingness within a particular group of customers thereby providing the company with opportunity to retain existing customers while attracting new ones and profitable ones (Brear, 2004).

Ahuja (2004) points out that for the continued development of the insurance industry, there is a need to review the 26 per cent limit on foreign equity ownership. In insurance, the extent of insurance business that an insurance company can underwrite depends on the amount of capital available with it. This is because it has to follow the solvency norms defined by the regulator. Underwriting higher risk thus calls for having a higher capital. Given the limited ability of the Indian partners to garner additional capital, there is a strong case for raising the limit so that the competition in insurance can blossom fully. Henneberger and Alexandre (2006) in a paper analyzed the employment effects in the service sector. It was shown that positive employment effects in services which have been taken for granted in the literature are likely only for a very limited subset of services, namely services that require physical proximity and whose users have high mobility costs. For all other services, negative effects of FDI on domestic employment are possible, and in some cases even likely.

Rastogi and Shankar (2007) claims that insurance industry contributes to the financial sector of an economy and also provides an important social 
Application of Cost Reduction ...

security net in developing countries. This study identifies the causes and the objectives with which the sector was reformed in 2000 to conclude that only in the last decade, the hybrid model of privatization with regulation adopted by the Government has yielded positive results and the sector has started to look up. The sector in its present form looks promising for the consumers, the insurers and the nation as a whole. Bhatia and Sethi (2007) in his paper reveals that a helpful approach of an insurer towards selling policy coverage and educating the policyholder in the event of terrorist attacks for coverage of such events has become imperative in the current state of affairs when attacks by terrorists have become unpredictable and causing severe damage and despair to the families of claimants. Good communication skills and intelligent diplomacy would lessen the ultimate pain that may be inflicted by the terrorist attacks on the families of policy holders. There should be empathy rather than finding out the loopholes and repudiating and rejecting the claims.

Viswanadham (2005) studied claims settlement operations of LIC of India with the objectives of evaluating performance in terms of both maturity and death claims before and after IRDA period. Claim settlement processing time expressed in speed ratios and adjudicatory measures of the corporation to redress the grievances of policyholders in settlement of claims. The study concluded that corporation should provide efficient service with courtesy in the matters of claim settlements. It should create highest trust in the minds of policyholders by establishing open and transparent grievance redressal procedure. As, satisfied customer will be a brand ambassador for the insurance company; claim settlement should be given more importance. Kalani, Salunkhe and Ahirrao (2013) examined claim settlement ratio of LIC with other insurance companies in India. Study observed that there are cases of frauds in claim settlement that may happened but if the policyholder uses proper precautions he will prevent himself from fraud. LIC of India provides better corporate services for settling the customers claim. D-mat may improve transparency and efficiency of the claim settlement. Authors studied comparison of claim settlement ratio of LIC with other life insurance industry and survey of policyholders and opinion 
Janapriya Journal of Interdisciplinary Studies, Vol. 6 (December 2017)

regarding claim settlement. Yadav and Mohania(2013) the study entitled claim settlement of life insurance policies in insurance services with special reference of Life Insurance Corporation of India. Authors have focused on management framework of LIC for the settlement; impacts of claim settlement on the sale of life insurance policies by LIC of India, claim settlement process followed by LIC of India, awareness towards claim settlement among customers and analyze quality of service provided by LIC of India for claim settlement.

Neuman(2007) worked on evaluation of performance of LIC of India. Objectives were to study importance of life insurance in human life, working of LIC, major attributes for the success of plans, operating efficiency, performance evaluation, growth of LIC. Overall study suggests that LIC should try to introduce new plans with facilities. LIC should strengthen their working, and should control operating cost. Many studies affirmed that prompt claims settlement contributed to organization performance, while some disagreed with the assertion that claims payment contribute to the insurance companies' performance. For instance, Butler and Francis (2010) discovered that prompt claims settlements has positive and significant relationship with insurance performance in terms of customer satisfaction and loyalty. Harry (2012) asserted that insurers need to take their claim handling function more seriously because if a claim is handled well, it results to higher customer retention but if handled poorly, policyholders will lose confidence in the insurer and this may damage its most cherished reputation. Omar (2005) assessed consumers' attitudes towards life insurance patronage in Nigeria and found out that there is lack of trust and confidence in the insurance companies due to slow or lack of claims settlements. Another major reason for this attitude is lack of knowledge about life insurance product. These findings mean that even if the share capital of insurance is increased in multiples, the performance of the industry could still be limited by the attitudes of Nigerians. In the same line, Yusuf, Gbodamasi and Hamadu (2009) conducted an empirical study on the attitudes of Nigerians towards insurance services. The study was conducted among 392 members of the public (insuring and non-insuring) to 
Application of Cost Reduction ...

gauge their awareness level and general attitudes towards insurance companies and their operations. The findings presented different demographical factors and attitudes towards insurance companies and their services.

Albert cited in Pandey (2007) noted that one of the reasons for low penetration of insurance business in the country is due to insurers' delay in settling claims. Insurance business is based on trust but is fraught with fraud as perpetrated by the various actors in this sector in Nigeria. Daniel (2013) also discovered that failure to settle claims and delay claims settlement are the causes of insurance failure in Nigeria. According to Oshinloye (2009), claim is an important aspect of insurance business in that poor claim settlement records of an insurance company may spell doom for such a company while a good reputation for good claim settlement records on the other hand may mean prosperity with respect to acquisition of more business." Insurance industry in Nigerian will experience growth and development as long as they are prepared and ready to settle all genuine claims on time. In the same vein, Augustine and Bamidele (2013) asserted that the image problem suffered till today by insurance companies in Nigeria is mainly because of what is seen as the insurance companies' posture of "smile to collect premium and frown to pay claim. The insuring publics do not even trust the insurers because they believe that they would always look for a way out at time of payment even when the claims are genuine. Hewitt (2006) also found that prompt claims settlement by insurance companies influence customer loyalty in advance countries. However, findings of Bates and Atkins (2007) and Ndubuishi (2008) conflicted with previous studies. They discovered that claims payment could be very costly as claims constitute the largest cost of an insurer and this has contributed to poor performance of insurance companies.

The main purpose of the research paper is to examine the satisfaction of customers towards life insurance claim settlement in Nepal 
Janapriya Journal of Interdisciplinary Studies, Vol. 6 (December 2017)

\section{Data and Methods}

In this study, the researcher has aimed to explore knowledge on satisfaction of customers towards life insurance claim settlement practices particularly 9 life insurance companies working in the country and claim settlement strategies for risk minimization and promotion of insurance in life insurance sector. This study was based on primary information and the data were quantitative in nature. Whole life insurance agents from different 9 life insurance companies were the population and 391 agents had been taken as samples of the study. Samples were taken by adopting convenient sampling technique. Closed-end questionnaires were used as a tool of data collection. Primary information'swere collected by using face to face interview and interview schedule.Descriptive studies are investigation of populations, not individuals. It is more practicable than questionnaires. In this method someone gives the clarification as and when needed. Schedule is a tool of obtaining answers to a set of questions from the respondents and investigator fills it by face to face interview. Both questionnaires and schedule are very similar but they also differ in some aspects; questionnaires are sent to the respondents by mail, where as a schedule is used directly in interviews.

Standard questions that were used by previous research studies in other countries of the globe were adopted to meet the internal validity of the research. About 10 percent of the sample (40) was chosen for the pre- test and then required modification was made after pre- test for measuring reliability of the study. Descriptive statistics and simple percentage have been used to analyze the data.

The study locations, is urban and rural areas of Nepal having diverse climate where population dynamics has been found high. The diverse geographic feature reflects the different demographic pattern existed in the region. The population has included the total life insurance agents working in regulation of the life insurance in the country. The data has been collected from local policy holders, insurance agents, and other stakeholders of the life insurance management. As it is difficult to collect whole data to study, sampling technique has been adopted for the present study. 
Application of Cost Reduction ...

About 391 respondent agents from each category were interviewed. According to Shoie (2003), the size of the sample should not be too large and not too small but it should be optimum based on logical criteria. There are many factors responsible for the selection of the sample, such as the size of the universe, availability of resources, degree of accuracy, heterogeneity and homogeneity of the universe, nature of the study, method of sampling adopted and the nature of respondents.

The raw data has been collected through different techniques as discussed above, needed editing and processing. In the first step, information has been carefully edited and incomplete answer has been evaluated according to the research theme. These collected information have been analyzed according to the objectives of research.

Meaningful tables has generated from the process of data. The data has been analyzed by using both qualitative and qualitative techniques. In this process description, explanation and generalization have been made using statistical tests. Similarly, discourse and statistical analysis has been linked with tables and figures have been used to achieve the objectives (Cresswell, 2013).

The computer readable forms of coded responses were entered into SPSS computer program. The SPSS for Windows provides a powerful statistical analysis and data management system in a graphical environment, using descriptive menus and simple dialog boxes. For this study, the descriptive statistics: frequency, correlation, and cross-tabulation were used in order to meet the research objectives and thereby to answer the defined research questions.

\section{Results and Discussion}

The response on availability of different policy as customer need were recorded based on the five point Likert Scale ranging from totally disagree to totally agree in which neutral was in the middle followed by partially disagree to partially agree. Table 1 shows the result of response of agents on availability of different policy as customer need in the market. 
Janapriya Journal of Interdisciplinary Studies, Vol. 6 (December 2017)

Table 1

Response on Availability of Different Policy as Customer Need

\begin{tabular}{lll}
\hline Indicators & Frequency & Percent \\
\hline Totally disagree & 45 & 11.5 \\
Partially disagree & 21 & 5.4 \\
Neutral & 87 & 22.3 \\
Partially agree & 199 & 50.9 \\
Totally agree & 39 & 10.0 \\
Total & 391 & 100.0 \\
\hline
\end{tabular}

Source: Field Data, 2014

The table 1 has shown that 50.9 percent respondent agents out of 391 with majority rated that they were partially agree that there is available of different policy as customer need. Only 45 that is $10 \%$ totally agreed that there is sufficient policies and products in the market according as customer need. However, $22.3 \%$ rated neutral, $11.5 \%$ totally disagree and $5.4 \%$ partially disagree with the market availability of the policies.

Table 2

Response on Service Provided to Poor and Marginalized

\begin{tabular}{lll}
\hline Indicators & Frequency & Percent \\
\hline Totally disagree & 43 & 11.0 \\
Partially disagree & 22 & 5.6 \\
Neutral & 89 & 22.8 \\
Partially agree & 204 & 52.2 \\
Totally agree & 33 & 8.4 \\
Total & 391 & 100.0 \\
\hline
\end{tabular}

Source: Field Data, 2014

The response of agents about the service available to poor and marginalized were recorded based on the five point Likert Scale ranging from totally disagree to totally agree in which neutral was in the middle. Table 2 shows the result of response of agents on service available to poor and marginalized in the country. 
Application of Cost Reduction ...

Table 2 has shown that 204 respondent agents that are 52.2\% out of 391 participants with majority rated that they were partially agree that there is service to poor and marginalized people in life insurance. About $11 \%$ totally disagreed, $5.6 \%$ partially disagreed, $22.8 \%$ remained neutral and $8.4 \%$ totally agreed to the fact that there is availability of services to poor and marginalized.

Claim return is the happiest moment to the clients in general. It is also measured as the rate of life insurance business success. The response of agents about the policy holders' satisfaction with the claim return was recorded based on the five point Likert Scale ranging from totally disagree to totally agree in which neutral was in the middle. Figure 1 shows the result of response of agents on policy holders' satisfaction level with claim settlement.

\section{Figure 1}

Response on Policy Holders Satisfied with Claim Settlement

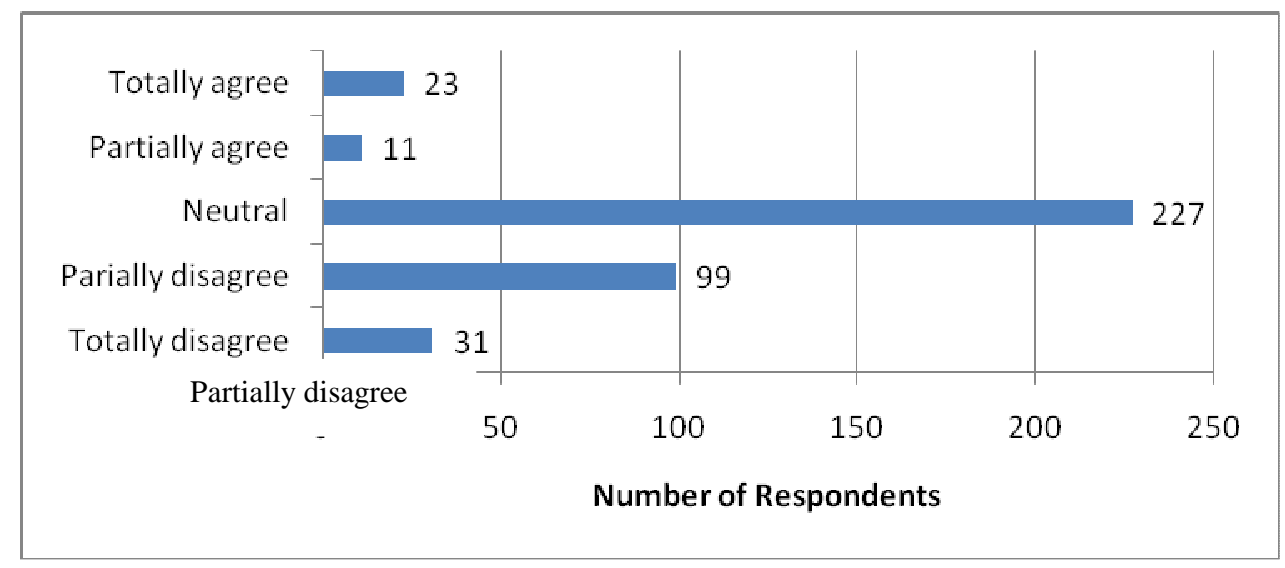

Source: Field Data, 2014

Figure 1 has shown that 227 respondent agents out of 391 with majority rated that they were neutral to the satisfaction of policy holders' on claim settlement. About 23 respondents were totally agree on full satisfaction, 11 rated that they were partially agree, 99 demonstrated that they were partially disagree and only 31 rated that they were totally disagree on the satisfaction towards policy holders' claim settlement. 
Janapriya Journal of Interdisciplinary Studies, Vol. 6 (December 2017)

Necessary improvement on claim process and policy sold were also felt needed during the assessment of the views of the respondents. The response of agents about the need of improvement on claim process and policy, were recorded based on the five point Likert Scale ranging from totally disagree to totally agree in which neutral was in the middle. Table 3 shows the result of response of agents on need of improving claim process and policy

\section{Table 3}

Response on Need of Improvement in Claim Process and Policy

\begin{tabular}{lll}
\hline Indicators & Frequency & Percent \\
\hline Totally disagree & 112 & 28.6 \\
Partially disagree & 16 & 4.1 \\
Neutral & 8 & 2.0 \\
Partially agree & 234 & 59.8 \\
Totally agree & 21 & 5.4 \\
Total & 391 & 100.0 \\
\hline
\end{tabular}

Source: Field Data, 2014

Table 3 has shown that 234 respondent agents that is $59.8 \%$ out of 391 with majority rated that they were partially agree to the need of necessary improvement on claim process, policy and regulations. About $28.6 \%$ rated that they were totally disagree for necessary improvement, $5.4 \%$ totally agreed for the improvement, $4.1 \%$ partially disagreed and only $2 \%$ remained neutral to the view.

The response of agents assessed about the time allotment for claim settlement taking 15 days as the normal and legal process interval. Table 4 shows the result of response of agents on timely settlement of claims within 15 days.

The table 4 has shown that 218 respondent agents that is $55.8 \%$ disagreed that the company took more than 15 days to settle the claim cases and paid without interest. About 173 (44.2\%) agreed that the claim process was paid with interest and it took more than 15 days. 
Application of Cost Reduction ...

Table 4

Claim Paid with Interest ( $>15$ days)

\begin{tabular}{lll} 
Description & Frequency & Percent \\
\hline No & 218 & 55.8 \\
Yes & 173 & 44.2 \\
Total & 391 & 100.0 \\
\hline
\end{tabular}

Source: Field Data, 2014

The response of agents about the belief that claim settlement process affects the growth of a company were recorded based on the three point Likert Scale ranging from totally disagree to totally agree in which partially agree was in the middle. Table 5 shows the result of response of agents on awareness about the belief that claim settlement process affects the growth of a company.

\section{Table 5}

Claim Settlement Process Affects Growth of a Company

\begin{tabular}{lll}
\hline Description & Frequency & Percent \\
\hline Disagree & 100 & 25.6 \\
Partially Agree & 172 & 44.0 \\
Agree & 119 & 30.4 \\
Total & 391 & 100.0 \\
\hline
\end{tabular}

Source: Field Survey, 2014

The table 5 has shown that 172 respondent agents that is $44 \%$ out of 391 rated that they partially agreed on the role of claim settlement process that affects growth of a company. About $30.4 \%$ agreed on the role of claim settlement that affects on the growth of the company where as $25.6 \%$ disagreed on the role of claim settlement that affects the growth of the company. 
Janapriya Journal of Interdisciplinary Studies, Vol. 6 (December 2017)

\section{Conclusions}

The study was conducted to study customer's satisfaction towards claim settlement of life insurance in Nepal. The evidences have been found in line with the fact that entrepreneurial development, launching innovative products, increased institutional delivery along with inbound claim calls attracts the customers for policy repurchase. It has claimed that life insurance has not only for security but has been taken as social prosperity through socio economic development.

Claims management is considered to be one of the most valuable possessions of any insurer. It is one aspect of insurance practice, the handling claims, which can make the image of insurance company. In fact, one of the principal functions of life insurance is the settlement of claims because it is the fear that a loss might occur that induces individuals and economic institutions to take out insurance policies. The problem of running an effective claims administration that would satisfy the customers, thereby earning the confidence of the customers and consequently inducing repurchase.

There was therefore a need to carry out a research with a view to finding out a more efficient and effective method of handling claims that will meet customers' satisfaction and in turn, redeem the sinking image of the insurance companies in the eyes of the insuring public, pave way for better performance and hence contribute to the economic development of Nepal. The emphasis here was to investigate the relationship between fast claims settlement and the sales and marketing of insurance products. Due to the constraints of time, the inability to measure the level of demand using the total sales and marketing figures of the selected company and the fact that the total amount of claims settled as reflected on their financial statements is not a true reflection of the extent of customer satisfaction in the claims service provided by the insurers, the researcher relied more heavily on the responses from the agents who were randomly picked from the company's clientele.There is lack of awareness about life insurance in the people. So, awareness programs should be launched by the Government through 
Application of Cost Reduction ...

Insurance Board so that everyone should be aware about the risks of the future. Risks are uncertainties because nobody knows the future.The Government has to keep the life insurance in its first priority. It has to manage an environment so that every people of Nepal feel safe by doing life insurance. It means government has to purchase the life insurance policies for its each and every citizen making mandatory.

There needs to be more research conducted in the field of claim settlement and the policy holders' understanding of life insurance policy use and claim settlement improvement in Nepal. Further research is needed to determine if these findings are transferable to a larger audience, or if they are unique to them.

\section{References}

Ahuja, R. (2004). Insurance: over the transition, Economic and Political Weekly, Aug, 1, 2004.

Augustine, O. \& Bamidele, E. (2013).Employees' empowerment and customers' satisfaction in insurance industry in Nigeria.Australian Journal of Business and Management Research, 3 (5).

Bates, I. \& Atkins, B. (2007).Management of Insurance Operations. London, Global Professional Publishing.

Brear, S. (2004).Chartered insurance institute (CII) course book, UK, Personal lines Insurance, CII learning solutions, pp 14/9-14/17.

Butler, S. \& Francis, P. (2010).Cutting the Cost of Insurance Claims, taking control of the process. Booz \& Co.

Daniel, F. (2013).Prompt Claim Settlement, the Best Advert for Insurance Firms. http://www.thisdaylive.com/articles/

Harry, B.O. (2012). The Effects of Slow Claims Settlement on the Sales and Marketing of Insurance Products; a Case Study of Enterprise Insurance Co. Ltd (EIC) -Takoradi Branch.Master thesis of kwame Nkrumah University of Science and Technology. 
Janapriya Journal of Interdisciplinary Studies, Vol. 6 (December 2017)

Henneberger, F. \&Alexandre, Z. (2006).Employment Effects of Foreign Direct Investment in the Service Sector: A Systematic Approach, Research Institute for Labor Economics and Labor Law, University of St. Gallen, Guisanstrasse 92, CH-9010 St. Gallen.

Hewitt, A. (2006). Claims Club Meeting. London, United Kingdom: Post Magazine.

Holyoake, J. \&Weipers, B. (2002). Insurance. A.I.T.B.S. Publishers and Distributers: NewDelhi.

Kalani, M., Salunkhe, H. A., \&Ahirrao, M. B. (2013).Comparative study of claim settlement ratio of LIC with other insurance companies in India, Indian Journal of Applied Research, 3 (5), 389-391.

Ndubuishi, M. O. (2008). Management of Insurance Business in Nigeria, retrieved on 23/02/2010from: http://findarticles.com/p/articles/

Neuman, W. L. (2007). Social research methods 'qualitative and quantitative approaches'. Delhi: Pearson Education.

Omar, O.E. (2005). The Retailing of life insurance in Nigeria: An assessment of consumers attitude. Journal of Retail Marketing Management Research, 1(1), 41-47.

Oshinloye , M. O. (2009). The Impact of Insurance Activities on Economic.

Rastogi, S. \& Shankar, R. (2007).Enhancing Competitiveness: The Case of the Indian Life Insurance Company, Indian Institute of Management, Kozhikode.

Rejda, G.E. (2008). Principles of Risk Management and Insurance. 10th ed. New York, Pearson Education.

Singh, H.B. (2010). Banking and Insurance. Asia Publication: Kathmandu.

Viswanadham, P. (2005). Claims settlement operations performance evaluation of LIC of India, The Indian Journal of Commerce, Vol. 58 (2), 80-90.

Yadav, R. K. \&Mohania, S. (2014). Claim settlement process of life insurance services - A case study of ICICI prudential life insurance 
Application of Cost Reduction ...

company, International Letters of Social and Humanistic Sciences, 24, 26-32.

Yusuf, H. O., Gbadamosi, A. \&Hamadu, D. (2009). Attitudes of Nigerians towards insurance services: An empirical study. African Journal of Accounting, Economics, Finance and Banking Research, 4 (4), 334346. 